\title{
Distalização dos molares superiores com aparelho Pendex unilateral: estudo piloto com radiografia panorâmica
}

\author{
Omar Gabriel da Silva Filho*, Eduardo César Almada Santos**, Ângela Priscila Junqueira de Lima Silva***, \\ André Pinheiro de Magalhães Bertoz ${ }^{\star \star \star \star}$
}

\begin{abstract}
Resumo
Objetivo: o presente ensaio científico põe em pauta o efeito imediato da distalização unilateral de molares superiores, lançando mão do distalizador intrabucal Pendex de ação unilateral. Metodologia: o estudo prospectivo foi conduzido em três pacientes na dentadura permanente madura, no estágio de adolescência, que apresentavam uma má oclusão Classe II, subdivisão. O aparelho Pendex foi instalado com a mola distalizadora de TMA, construída apenas no lado direito. A metodologia baseou-se nas radiografias panorâmicas inicial e pós-distalização para quantificar a inclinação axial mesiodistal dos molares superiores. Resultados e Conclusões: os resultados mostraram que os molares do lado esquerdo mantiveram sua inclinação mesiodistal inicial, sugerindo ancoragem, enquanto os molares do lado direito foram inclinados para distal, à semelhança do que ocorre com a distalização simétrica dos molares superiores, obtida com o aparelho Pendex convencional. Os primeiros molares foram inclinados $11,5^{\circ}$, enquanto os segundos molares foram inclinados $21^{\circ}$ para distal.
\end{abstract}

Palavras-chave: Aparelho Pendex. Má oclusão Classe II. Distalização. Distalização unilateral. Deformidades dentofaciais.

\section{INTRODUÇÃO}

A não extração de pré-molares na correção de uma má oclusão Classe II representa uma razão convincente para distalizar os molares superiores. O objetivo final da mecânica sagital é devolver uma relação de Classe I, beneficiando a relação interarcos e intra-arco, com a presença de todos os dentes permanentes. Sabe-se, comprovadamente, que é possível distalizar os primeiros molares superiores usando ancoragem extrabucal ${ }^{2,4}$, com a distalização indireta dos segundos molares, independentemente da condição de erupção desses últimos. E mais, teórica e pragmaticamente, é possível distalizar os primeiros molares superiores de corpo, fazendo com que a linha de ação de força passe pelo centro de resistência dos molares. Isso é conseguido com a inclinação para cima do braço externo do aparelho extrabucal (AEB). Além dessa propriedade exclusiva do AEB,

* Ortodontista do Hospital de Reabilitação de Anomalias Crânio-Faciais de Bauru - HRAC-USP. Coordenador do Curso de Atualização em Ortodontia Preventiva e Interceptiva da PROFIS.

Professor Assistente Doutor da Disciplina de Ortodontia do Departamento de Odontologia Infantil e Social da Faculdade de Odontologia de Araçatuba - UNESP.

*** Aluna do Curso de Especialização em Ortodontia da Sociedade de Promoção do Fissurado Lábio-Palatal - PROFIS.

** Aluno do Curso de Doutorado da Disciplina de Ortodontia do Departamento de Odontologia Infantil e Social da Faculdade de Odontologia de Araçatuba - UNESP. 
as forças reacionais da mecânica estão fora da boca, o que o diferencia e o torna mecanicamente superior a todos os aparelhos distalizadores intrabucais. Portanto, os aparelhos distalizadores são congregados em dois grupos, o consagrado AEB e os diversos distalizadores intrabucais contemporâneos. Dentre os distalizadores intrabucais, o aparelho Pendex, derivado do aparelho Pêndulo, consiste num aparelho fixo de ancoragem intramaxilar muito propagado e modificado na literatura pertinente ${ }^{5-11,13,15,17-24,31-35,41}$.

Sem dúvida, a distalização dos molares sem o uso do tradicional AEB deixou de ser uma utopia e representa um salto na evolução dos dispositivos mecânicos ortodônticos. Aliás, representa progresso de conotação prática, uma vez que aumenta a expectativa de eliminar uma variável importante no êxito do tratamento ortodôntico: a cooperação do paciente. Se por um lado têm a vantagem da força incessante, por outro, os distalizadores intrabucais apresentam inconvenientes mecânicos recorrentes, que afrontam o ortodontista. Destaca-se a imprevisibilidade do resultado, exigindo a necessidade do controle individual ao longo do tratamento. Afinal, avaliar riscos faz parte da equação científica: custo $\mathrm{x}$ benefício.

O monitoramento abrangente da distalização dos molares superiores foi recentemente publicado pela disciplina de Ortodontia da Faculdade de Odontologia de Araçatuba, Unesp, em artigos ${ }^{31,32,33}$ que constituem uma trilogia, utilizando telerradiografia lateral ${ }^{31}$, radiografia panorâmica ${ }^{32}$ e modelos de gesso ${ }^{33}$, num estudo prospectivo com o aparelho Pendex clássico, tal qual desenvolvido por Hilgers $^{17,18,19}$, aplicado bilateralmente. Os estudos de Araçatuba demonstraram que os efeitos do aparelho Pendex resumem-se em: inclinar os primeiros e segundos molares superiores para distal, aumentando o perímetro do arco dentário superior, com controle transversal e vertical. Claro que há perda de ancoragem, diagnosticada pela vestibularização dos incisivos superiores ${ }^{31}$.

Na má oclusão Classe II subdivisão típica, a assimetria reside no arco dentário inferior, que encontra-se desviado para o lado da Classe II $^{20}$.
Isso implica na normalidade do arco dentário superior. O diagnóstico clínico baseia-se fundamentalmente no comportamento das linhas médias dentárias em relação à linha média facial. A linha média superior está centralizada, enquanto a linha média inferior está desviada para o lado da Classe II. No entanto, ocasionalmente, na subdivisão, o problema pode estar localizado no arco dentário superior, condição em que o tratamento exige distalização ou extração superior unilateral. Nesse caso, a distalização unilateral dos molares pode ser conseguida com o AEB, que possui versatilidade para a aplicação de forças excêntricas ${ }^{3}$. A distalização unilateral pode também ser alcançada com os distalizadores unilaterais. Para alcançar a distalização unilateral com o Pendex ou Pêndulo elimina-se uma das molas distalizadoras. Isso talvez corresponda à vantagem de demandar menos ancoragem, já que a reação do aparelho é intrabucal.

O objetivo do presente trabalho consiste em observar, mediante o emprego da radiografia panorâmica, o efeito imediato induzido pelo aparelho Pendex unilateral nos molares superiores, usando como referência para comparação os dados de Araçatuba para a distalização simétrica com o aparelho Pendex convencional.

\section{MATERIAL E MÉTODOS \\ Material de controle (Amostra prospectiva prévia $^{31,32,33}$ )}

O grupo controle utilizou uma amostra de 30 radiografias panorâmicas, tomadas no início e no final da distalização com o aparelho Pendex dos primeiros molares superiores permanentes (Fig. 15), de 15 jovens brasileiros tratados no Curso de pós-graduação, nível de mestrado da Faculdade de Odontologia de Araçatuba - UNESP, por um único profissional. Todos os pacientes, sendo 9 do gênero masculino e 6 do gênero feminino, apresentavam relação molar de Classe II em ambos os lados, com média de idade de 11 anos e 3 meses, numa faixa etária entre 9 e 15 anos. Convém salientar que não foram incluídos pacientes com agenesias, perda 
precoce de dentes decíduos e pacientes submetidos a qualquer tipo de tratamento ortodôntico prévio.

Para a coleta de dados, a formação do grupo controle foi devidamente aprovada pelo Comitê de Ética em Pesquisa em Humanos da Faculdade de Odontologia de Araçatuba - UNESP.

\section{Material experimental (Distalização unilateral)}

O grupo experimental (Distalização unilateral) utilizou uma amostra de 6 radiografias panorâmicas, expostas nas figuras 7,8 e 10, tomadas no início e no final da distalização dos molares superiores permanentes do lado direito, com o aparelho Pendex unilateral, de 3 jovens brasileiros tratados no Curso de Especialização da Profis - Bauru, sendo 1 do gênero masculino e 2 do gênero feminino. Os 3 pacientes apresentavam relação molar de meia Classe II do lado direito, com média de idade de 12 anos e 6 meses, numa faixa etária entre 11 e 14 anos. O planejamento ortodôntico incluiu a distalização unilateral dos molares superiores do lado direito, com a intenção de corrigir a relação interarcos e aumentar o perímetro do arco dentário superior com mecânica ortodôntica, já que os pacientes possuíam padrão I. O diagnóstico nos três pacientes era uma má oclusão Classe II, subdivisão, padrão I, com apinhamento unilateral superior do lado direito e linhas médias dentárias coincidentes com a linha média facial. A assimetria sagital localizava-se no arco dentário superior.

O efeito da mola distalizadora foi considerado concluído quando a relação molar estava assenta- da em Classe I. Ainda assim, o aparelho Pendex foi mantido na boca durante a distalização do segundo pré-molar, servindo de contenção para o molar distalizado. O aparelho Pendex foi substituído pela barra transpalatina depois que o dente 15 encostou no dente 16. Depois da remoção do Pendex, a barra transpalatina passou a funcionar como contenção para o molar distalizado. Usouse elástico de Classe II do lado direito durante a distalização do canino superior, como reforço para a contenção dos molares distalizados.

\section{Método}

\section{Descrição dos passos do tratamento (Amostra prospectiva prévia ${ }^{31,32,33}$ )}

O aparelho distalizador intrabucal Pendex utilizado no grupo controle (Fig. 1) constituiu-se de bandas nos primeiros pré-molares e primeiros molares permanentes superiores, apoios oclusais na distal dos segundos pré-molares, parafuso expansor, botão acrílico e molas distalizadoras de TMA. Dos 15 pacientes apenas 1 apresentava os primeiros molares decíduos superiores na cavidade bucal. Para este caso não foi realizada a bandagem dos primeiros molares decíduos e sim a confecção de apoios oclusais na mesial dos respectivos dentes, com fio de aço 0,9mm (Fig. 2). Antes da cimentação do aparelho distalizador, as molas foram ativadas de forma a ficarem paralelas à rafe palatina mediana (Fig. 3). De acordo com Hilgers ${ }^{18}$, cerca de 1/3 desta força é anulada durante o encaixe do segmento intratubo da mola distalizadora no tubo palatino do primeiro

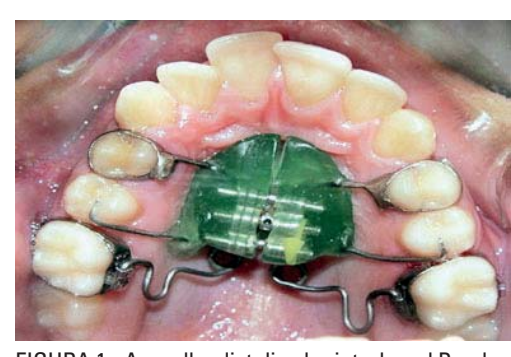

FIGURA 1 - Aparelho distalizador intrabucal Pendex avaliado no grupo controle.

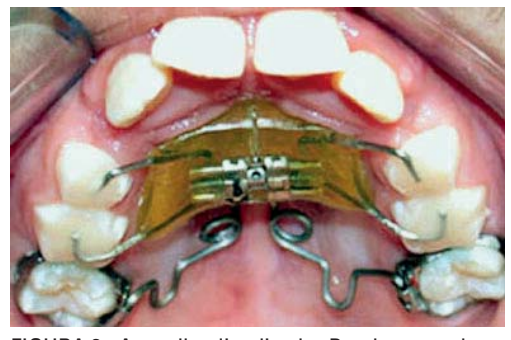

FIGURA 2 - Aparelho distalizador Pendex quando os primeiros pré-molares não haviam irrompido. Note a presença dos apoios oclusais na mesial dos primeiros molares decíduos superiores.

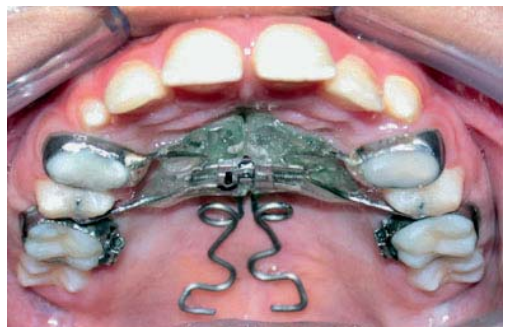

FIGURA 3 - Mola distalizadora de TMA paralela à rafe palatina mediana. 


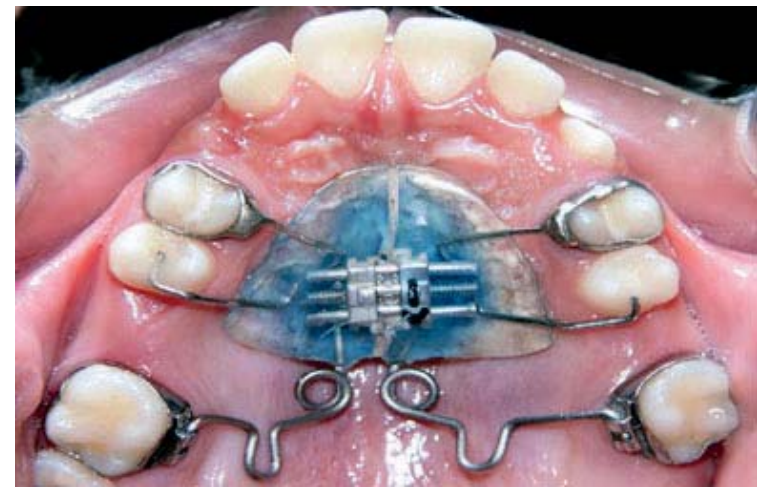

FIGURA 4 - Vista oclusal dos primeiros molares distalizados, após aproximadamente 5,2 meses de tratamento.

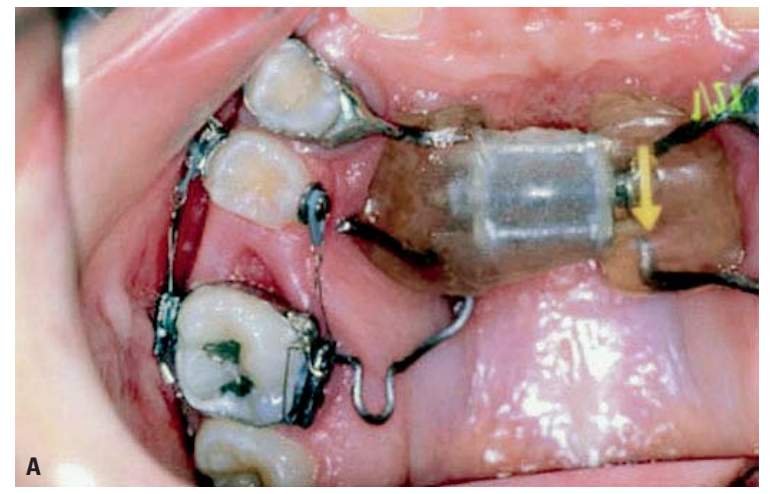

FIGURA 6 - Pendex unilateral ancoragem (lado esquerdo).

molar superior permanente. A força registrada pelo tensiômetro foi de aproximadamente $300 \mathrm{~g}$ por lado. As avaliações foram realizadas quinzenalmente e as ativações das molas a cada trinta dias, conforme a necessidade de correção da relação molar. $\mathrm{O}$ aparelho foi removido quando os primeiros molares estavam sobrecorrigidos e o tempo gasto para alcançar este resultado foi, em média, de 5,2 meses (Fig. 4). No momento em que a cúspide mesiovestibular do primeiro molar superior estava ocluindo com o sulco mesiovestibular do primeiro molar inferior era realizada uma dobra anti-inclinação no segmento intratubo da mola distalizadora com $15^{\circ}$ de inclinação para oclusal (Fig. 5). Almejava-se com esta dobra promover a verticalização da raiz, conferindo à distalização do primeiro molar superior permanente um movimento próximo ao de corpo.

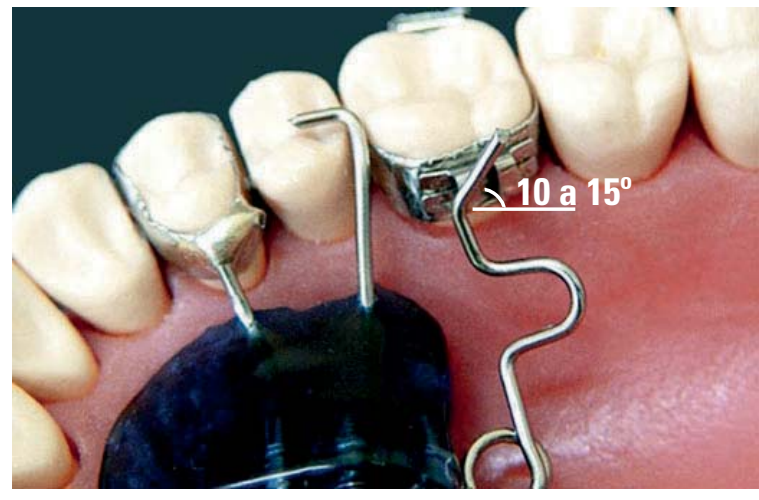

FIGURA 5 - Dobra anti-inclinação de $15^{\circ}$ para oclusal com o intuito de promover a verticalização das raízes do primeiro molar permanente superior após a distalização da coroa.

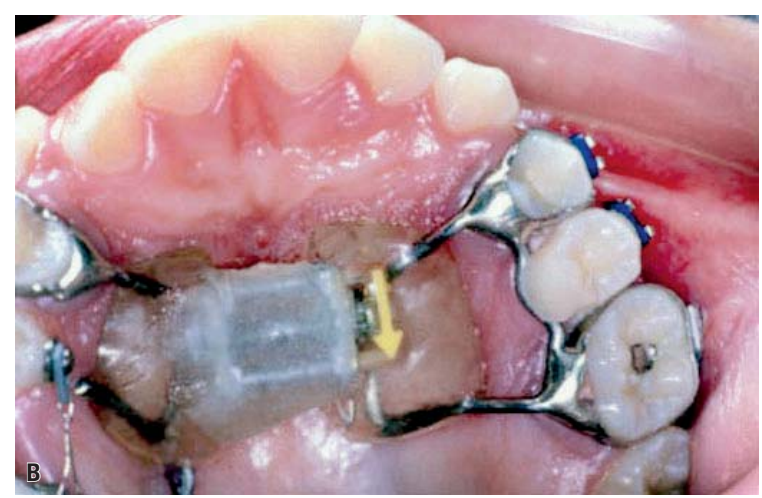

r superior do lado direito. A) Lado da distalização (lado direito), B) Lado de Método experimental: modificação do Pendex para força unilateral

A confecção e instalação do aparelho Pendex unilateral (Fig. 6) seguiram os passos operacionais do Pendex bilateral da amostra de Araçatuba. A única diferença encontra-se na eliminação da mola distalizadora de TMA do lado esquerdo. Assim, a ancoragem passou a ser maior, contando com o quadrante superior esquerdo (Fig. 6B). A mola de TMA foi inserida ativada no tubo palatino do primeiro molar e não foi ativada mais até o momento da retirada do aparelho, em torno de 6 meses depois. $\mathrm{O}$ acionamento do parafuso expansor obedeceu o protocolo de expansão rápida da maxila, sendo uma volta completa por dia, distribuída em 2/4 de volta pela manha e 2/4 de volta à noite, até completar o efeito transversal. 


\section{Descrição da metodologia sobre a radiografia panorâmica}

A inclinação mesiodistal do longo eixo dos primeiros e segundos molares superiores foi avaliada por intermédio das radiografias panorâmicas iniciais (Fig. 7) e pós-distalização dos molares (Fig. 8). O traçado da radiografia panorâmica na folha de papel de acetato de celulose (Ultraphan - 3M) constituiu-se de uma linha representativa do plano palatino (ENP-ENP) e do contorno dos primeiros e segundos molares superiores, do lado direito e esquerdo (Fig. 9). Após o traçado radiográfico, foram medidos os ângulos formados entre o longo eixo dos primeiros e segundos molares superiores, dos lados direito e esquerdo, em relação à linha representativa do plano palatino (Fig. 9). O desenho das estruturas de interesse nas radiografias panorâmicas, o traçado das linhas sobre o desenho anatômico e a medição dos ângulos foram realizados por um profissional e conferidos por outro.

\section{RESULTADOS}

A tabela 1 descreve os valores individuais e a tabela 2 mostra a estatística descritiva, com as médias e os desvios-padrão. As tabelas 1 e 2 representam o comportamento mesiodistal dos primeiros e dos segundos molares superiores, do lado direito e do lado esquerdo, submetidos ao distalizador intrabucal

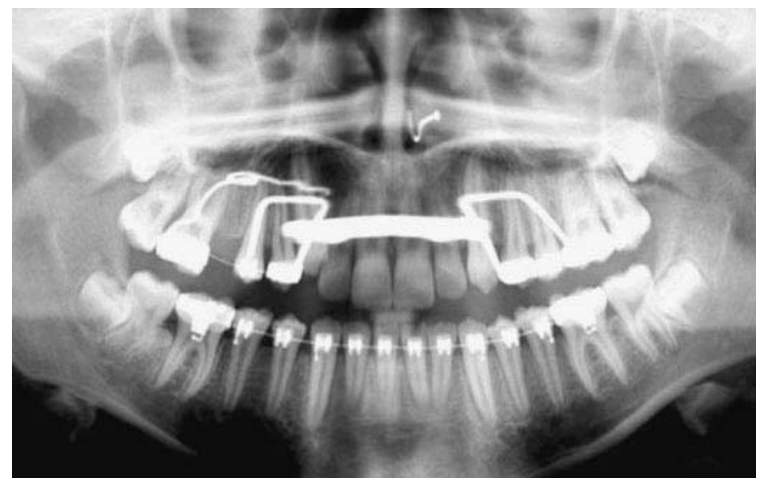

FIGURA 8 - Radiografia panorâmica pós-distalização dos primeiros e segundos molares superiores do lado direito (paciente N.G.F.). Observa-se a abertura de espaço entre o segundo pré-molar e o primeiro molar superior, do lado direito.
Pendex unilateral, do lado direito. A tabela 3 apresenta os dados do trabalho de Santos et al. ${ }^{32}$, para ilustrar o comportamento dos primeiros e dos segundos molares superiores quando submetidos à distalização com um aparelho Pendex bilateral (simétrico).

\section{DISCUSSÃO}

Desde a década de 1980, quando o desenvolvimento tecnológico possibilitou a liberação de força suave e contínua contra os molares superiores, usando ancoragem intramaxilar fixa, a Ortodontia parece ter se imbuído da noção de que é possível distalizar os molares com os aparelhos distalizadores intrabu-

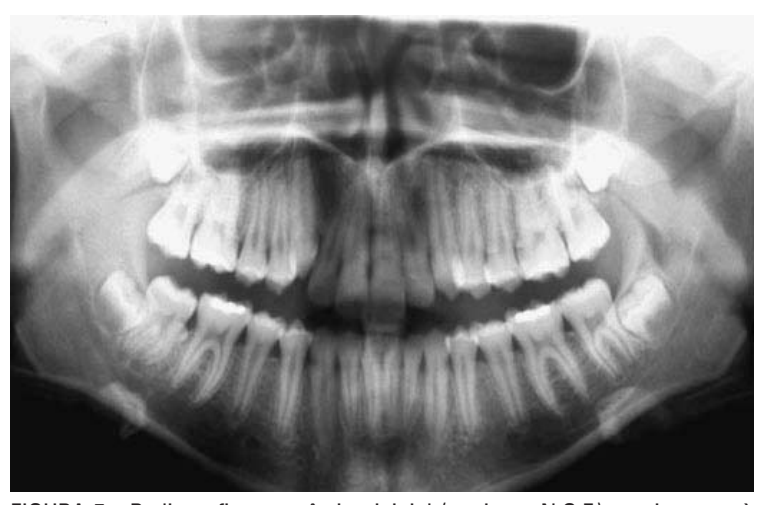

FIGURA 7 - Radiografia panorâmica inicial (paciente N.G.F.) previamente à instalação do aparelho distalizador intrabucal Pendex, no estágio de maturidade oclusal (segundos molares permanentes irrompidos).

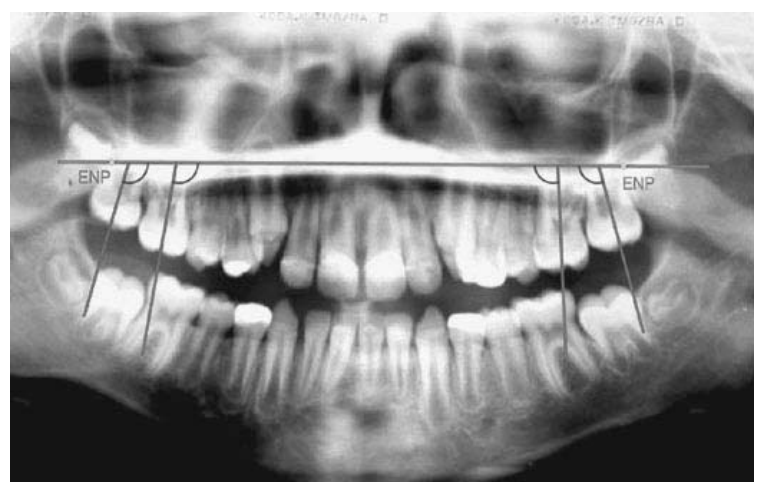

FIGURA 9 - Radiografia panorâmica demonstrando a metodologia utilizada para avaliar o comportamento mesiodistal dos molares superiores ${ }^{29}$. A linha horizontal representa o plano palatino (unindo os pontos Espinha Nasal Posterior). As linhas verticais representam o longo eixo dos primeiros e segundos molares superiores. 0 comportamento dos molares superiores foi avaliado pelos ângulos formados pelas linhas verticais e horizontal. 
cais. Esse desafio é uma realidade comprovada pelo espaço generoso que a literatura vem dedicando aos distalizadores intrabucais, inclusive em literatura pátria ${ }^{1,5,12,13,25,26,28,29,36-39,41}$. Os distalizadores intrabucais são capazes de cumprir a função indicada pelos seus nomes, isto é, distalizar primeiros e/ou os segundos molares superiores, como explicitado nas figuras 4 e 6, mediante emprego do Pendex. Essa tônica foi firmada na única pesquisa onde os autore ${ }^{40}$ compararam, mediante o emprego de telerradiograifa lateral, a distalização conseguida com o AEB e com o Pendex ${ }^{40}$. Ambos os aparelhos foram hábeis em distalizar os primeiros e os segundos molares superiores em quantidades semelhantes, entre $3,15 \mathrm{~mm}$ e $3,81 \mathrm{~mm}$ para os primeiros molares e entre $2,04 \mathrm{~mm}$ e $2,27 \mathrm{~mm}$ para os segundos molares, contando com a vantagem do menor tempo dispendido de tratamento para o aparelho Pendex, (em torno de 7 meses). É oportuno lembrar que, nas orientações fornecidas por Hilgers, o Pendex distaliza até $5 \mathrm{~mm}$ num período de tempo entre 3 e 4 meses. De fato, o tempo menor dispendido nas distalizações parece ser também característica de outros aparelhos, como o Jones Jig ${ }^{16}$.

É certo que no transcorrer das últimas décadas muitos ortodontistas têm vivenciado a distalização dos molares com aparelhos intrabucais na clínica cotidiana. No entanto, a imprevisibilidade dos resultados obtidos expõe a fragilidade mecânica implícita no desenho desses aparelhos. Do ponto de vista mecânico, os distalizadores intrabucais possuem duas desvantagens importantes, que os singularizam perante $\mathrm{o}$ seu antecessor clássico, o AEB. Essas são: 1) a perda de ancoragem, representada pela movimentação em sentido contrário dos dentes anteriores aos molares e 2) a inclinação dos molares distalizados, representada pela resistência das raízes à distalizacão.

$\mathrm{O}$ primeiro inconveniente dos distalizadores intrabucais refere-se à perda de ancoragem, condição ausente na distalização com o AEB. Os $3 \mathrm{~mm}$

Tabela 1 - Estatística descritiva com os valores individuais, acrescidos das médias e desvios-padrão, dos ângulos representativos dos primeiros e dos segundos molares do lado direito e esquerdo dos três pacientes que utilizaram Pendex unilateral do lado direito.

\begin{tabular}{|c|c|c|c|c|c|c|c|c|c|c|c|c|}
\hline & $\begin{array}{l}\text { P1/LD } \\
1^{\circ} \mathrm{M}\end{array}$ & $\begin{array}{c}\text { P2/LD } \\
1^{\circ} \mathrm{M}\end{array}$ & diferença & $\begin{array}{c}\mathbf{P} 1 / \mathbf{L D} \\
2^{\circ} \mathbf{M}\end{array}$ & $\begin{array}{c}\text { P2/LD } \\
2^{\circ} \mathbf{M}\end{array}$ & diferença & $\begin{array}{c}\mathrm{P} 1 / \mathrm{LE} \\
1^{\circ} \mathrm{M}\end{array}$ & $\begin{array}{c}\mathrm{P} 2 / \mathrm{LE} \\
1^{\circ} \mathrm{M}\end{array}$ & diferença & $\begin{array}{l}\mathrm{P} 1 / \mathrm{LE} \\
2^{\circ} \mathrm{M}\end{array}$ & $\begin{array}{l}\mathrm{P2} / \mathrm{LE} \\
2^{\circ} \mathrm{M}\end{array}$ & diferença \\
\hline 1 & 106,5 & 125 & 18,5 & 104 & 133 & 29 & 112 & 115 & 3 & 112 & 120 & 7 \\
\hline 2 & 106 & 110 & 4 & 117 & 134 & 17 & 110 & 110 & 0 & 120 & 119 & -1 \\
\hline 3 & 102 & 114 & 12 & 111 & 128 & 17 & 107,5 & 105 & $-2,5$ & 115 & 117 & 2 \\
\hline
\end{tabular}

P1 - primeira panorâmica; P2 - segunda panorâmica; $1^{\circ} \mathrm{M}$ - primeiro molar superior; $2^{\circ} \mathrm{M}$ - segundo molar superior; LD - lado direito; LE - lado esquerdo.

Tabela 2 - Médias e desvios-padrão das alterações sagitais (inclinação mesiodistal) dos primeiros e segundos molares superiores, do lado direito e esquerdo, dos três pacientes submetidos ao aparelho Pendex unilateral do lado direito.

\begin{tabular}{|c|c|c|c|c|c|c|c|c|}
\hline & \multicolumn{2}{|c|}{ LD $1^{\circ} M$} & \multicolumn{2}{|c|}{ LD $2^{\circ} \mathrm{M}$} & \multicolumn{2}{|c|}{ LE $1^{\circ} M$} & \multicolumn{2}{|c|}{ LE $2^{\circ} \mathbf{M}$} \\
\hline & média & d.p. & média & d.p. & média & d.p. & média & d.p. \\
\hline inicial & 104,83 & 2,47 & 110,67 & 6,51 & 109,83 & 2,25 & 115,67 & 4,04 \\
\hline final & 116,33 & 7,77 & 131,67 & 3,21 & 110 & 5 & 118,67 & 1,53 \\
\hline diferença & 11,5 & 7,26 & 21 & 6,93 & 0,17 & 2,75 & 2,67 & 4,04 \\
\hline
\end{tabular}

$1^{\circ} \mathrm{M}$ - primeiro molar superior; $2^{\circ} \mathrm{M}$ - segundo molar superior; $\mathrm{LD}$ - lado direito; LE - lado esquerdo

Tabela 3 - Médias e desvios-padrão das alterações sagitais (inclinação mesiodistal) dos primeiros e segundos molares superiores, do lado direito e esquerdo, dos pacientes submetidos ao aparelho Pendex bilateral (simétrico). Dados extraídos de Santos et al. ${ }^{32}$

\begin{tabular}{|c|c|c|c|c|c|c|c|c|}
\hline & \multicolumn{2}{|c|}{ LD $1^{\circ} \mathrm{M}$} & \multicolumn{2}{|c|}{ LD $2^{\circ} \mathrm{M}$} & \multicolumn{2}{|c|}{ LE $1^{\circ} \mathrm{M}$} & \multicolumn{2}{|c|}{ LE $2^{\circ} \mathbf{M}$} \\
\hline & média & d.p. & média & d.p. & média & d.p. & média & d.p. \\
\hline inicial & 99,96 & 6,28 & 114,14 & 8,41 & 98,82 & 5,69 & 114,18 & 9,89 \\
\hline final & 119,32 & 8,72 & 130,61 & 8,74 & 121,39 & 8,72 & 134,14 & 11,54 \\
\hline diferença & 19,36 & & 16,47 & & 22,57 & & 19,96 & 4,04 \\
\hline
\end{tabular}


médios de distalização dos molares, conseguidos com o uso do $\mathrm{AEB}^{2,4,40}$ não incorporam perda de ancoragem. Perda de ancoragem durante a distalização dos molares significa mesializacão dos prémolares $^{7,8,9,10,15}$ e vestibularizacão dos incisivos superiores ${ }^{6,7,9,15,28}$ como resposta à reação da distalizacão dos molares. Isso justifica-se porque nesse aparelho, diferentemente do que acontece com o AEB, o princípio newtoniano de ação e reação da mecânica encontra-se dentro da boca. Claro que o objetivo utópico da ancoragem dos distalizadores intrabucais, apoiada em dentes e/ou na mucosa, é o de anular a reação advinda da força de distalização dos molares. Pressupõe-se, portanto, que a estrutura de ancoragem representa componente essencial do aparelho e necessita de vigor físico.

Definitivamente, a distalização dos molares com AEB não conta com a mesialização dos pré-molares e inclinação vestibular dos incisivos superiores. $\mathrm{Na}$ verdade, quando se distaliza os molares superiores com AEB, os pré-molares têm comportamento contrário ao verificado com os distalizadores intrabucais. Existe uma tendência para a distalização espontânea dos pré-molares durante a distalização dos molares com o $\mathrm{AEB}^{16,30,40}$. Isso é tão verdade que, nas distalizações dos molares em época adequada, no final da dentadura mista, verifica-se que os pré-molares, em especial os segundos, tendem a acompanhar em menor proporção a distalização dos primeiros molares.

A segunda desvantagem mecânica dos distalizadores intrabucais refere-se à impossibilidade de distalização dos molares, cumprindo um movimento de translação. Embora os diferentes aparelhos intrabucais lancem mão de recursos para controlar o centro de rotação (Fig. 5), até o momento isso ainda é improvável. O estudo cefalométrico com a amostra de Araçatuba registrou uma distalização da coroa dos primeiros molares de cerca de $4 \mathrm{~mm}$ e nenhuma distalização do ápice dos molares ${ }^{31}$, caracterizando um movimento de inclinação controlada. Comparando-se o movimento distal dos molares, conseguido com o AEB e com o Pendex, concluiu-se que ambos os distalizadores têm efeito semelhantes ${ }^{40}$.
Não que o molar foi distalizado de corpo, mas sim que em ambos os processos de distalização os molares foram inclinados para distal, comprovando a dificuldade em se controlar o centro de rotação dos molares durante a distalização dos mesmos. O movimento distal da raiz durante a aplicação do $\mathrm{AEB}$ é conseguido graças à inclinação do braço externo para cima $^{27}$. A experiência demonstra que, se é difícil controlar o centro de rotação dos molares usando o AEB, é praticamente impossivel ter esse controle quando se usa um distalizador intrabucal ${ }^{31,32,33}$.

Parece claro que o reconhecimento desses fatores limitantes impede o total esquecimento do AEB como distalizador, dando ao clínico a lucidez, ou seja a coerência, necessária para conseguir dos distalizadores resultados compatíveis com uma boa finalização ortodôntica, como por exemplo: 1) planejar uma distalização de magnitude compatível com a finalização, de até meia Classe II; 2) acompanhamento cuidadoso dos efeitos induzidos pela mecânica durante a distalização; 3) usar distalizadores intrabucais quando se deseja a distalização dos molares em pacientes em fase de crescimento e com deficiência maxilar; 4) usar ancoragens mais abrangentes na distalização, como por exemplo fazer distalização unilateral (Fig. 6), onde se pode usar todo o arco dentário superior como ancoragem. Não bastando os cuidados no planejamento e no transcorrer do procedimento de distalização, a perda da distalização depois da remoção do distalizazor é outra preocupação do clínico, devido principalmente ao efeito de inclinação conseguido com a distalização.

A total dependência que o ortodontista tem do paciente para o AEB exercer sua competência fez com que a intelectualidade ortodôntica deixasse de ver no AEB a única referência ideológica para distalização dos molares superiores. Os distalizadores intrabucais vieram resgatar a chance de distalização dos molares quando o AEB está contra-indicado. O objetivo terapêutico é o mesmo: a distalização dos molares. Porém, seus estilos mecânicos são completamente diferentes, tanto no que se refere à natureza quanto à magnitude da força liberada. 
O AEB distaliza os molares com força entre 400 e 500g, com uso intermitente em torno de 16 horas por dia ${ }^{40}$. O Pendex distaliza os molares com força contínua entre 200 e 300g. A opção por um desses distalizadores, intrabucal ou extrabucal, não é uma simpatia gratuita, baseia-se em princípios filosóficos e na cooperação do paciente. Quando a opção é o distalizador intrabucal, o ortodontista passa a encarar a perda imprevisível de ancoragem e a inclinação inevitável dos molares como desvantagens que precisam ser aceitas e contornadas, subseqüentemente, de alguma maneira.

A inclinação dos primeiros e segundos molares foi mensurada na presente pesquisa mediante emprego da radiografia panorâmica, para avaliar o comportamento dos molares superiores diante de um Pendex com mola distalizadora unilateral. Representa um estudo prospectivo piloto, já que apenas três pacientes receberam este distalizador unilateral (Fig. 10). Nos três pacientes, a meta terapêutica era corrigir a Classe, unilateralmente, e aumentar o perímetro do arco dentário superior para correção de apinhamento, o que foi conseguido com êxito, como demonstrado radiograficamente na figura 10 . Os molares superiores do lado direito foram distalizados com o aparelho Pendex unilateral, uma modificação do precursor Pendex bilateral que tem sido divulgado na literatura desde 1991, por Hilgers ${ }^{17}$. $\mathrm{Na}$ amostra de Araçatuba ${ }^{31,32,33}$, que serviu de referência para comparação com a distalização unilateral do presente artigo, a distalização média de $4 \mathrm{~mm}$ foi conseguida num período médio de 5 meses, o que corresponde a uma velocidade de $0,8 \mathrm{~mm}$ ao mês $^{31}$.

No presente estudo, a inclinação mesiodistal dos primeiros e segundos molares, dos dois lados, foi quantificada em relação ao plano palatino traçado nas radiografias panorâmicas pré-distalização e pósdistalização (Fig. 9). Os dados expostos na tabela 2 mostram que os molares do lado direito, que receberam a mola distalizadora de TMA, inclinaram-se para distal. O primeiro molar mostrou uma inclinação distal de $11,5^{\circ}$, enquanto o segundo molar inclinou $21^{\circ}$. Esse resultado não é supreendente, uma vez que a literatura é unânime em demonstrar que os molares inclinam para distal enquanto distalizam, com o emprego do aparelho Pêndulo ou Pendex. Isso vem comprovar a dificuldade em controlar o centro de rotação dos molares durante a distalização com aparelhos intrabucais, mesmo quando a força é unilateral, e mesmo quando se aplicam mecanismos mecânicos com intenção de distalizar a raiz, como se vê na figura $5^{8,9,10,31}$.

Os trabalhos ${ }^{6-11,15,17-21,24,31}$ com cefalometria lateral concordam com a inclinação distal da coroa dos molares distalizados com o aparelho Pendex bilateral entre $3,1^{\circ}$ e $15,7^{\circ}$. Essa inclinação distal foi confirmada também em radiografias panorâmicas, com valores entre $19^{\circ}$ e $22^{\circ}$ para os primeiros molares e entre $16^{\circ}$ e $19^{\circ}$ para os segundos molares (Tab. 3$)^{32}$.

Pela imagem das radiografias panorâmicas, a condição de erupção dos segundos molares superiores não era a mesma nos três pacientes. Em dois dos pacientes estudados ( $\mathrm{n}^{\circ} 2$ e 3 ) os segundos molares permanentes estavam completamente irrompidos, atingindo o plano oclusal (Fig. 7, 8, 10). No outro paciente $\left(\mathrm{n}^{\circ} 1\right)$ os segundos molares superiores, em erupção, não haviam aflorado na cavidade bucal (Fig. 10A, B). Será que a condição de erupção dos segundos molares superiores interferiu na resposta dos primeiros molares à distalização? Os resultados expressos na tabela 1 demonstram que a inclinação distal do primeiro molar foi bem maior na ausência clínica do segundo molar, $18,5^{\circ}$, do que quando o segundo molar estava presente clinicamente, $4^{\circ} \mathrm{e}$ $12^{\circ}$. A maioria dos estudos pertinentes não dá importância para o estágio de erupção dos segundos molares superiores, quando da distalização dos primeiros molares com distalizadores intrabucais, delatando pouca influência desses dentes na resposta dos primeiros molares sob influência do Pêndulo ou Pendex ${ }^{7,10,15,21}$. Porém, o artigo de Kinzinger et al. ${ }^{24}$ estabelece que a condição de erupção dos segundos molares superiores influencia significativamente na distalização dos primeiros molares. O germe do segundo molar não irrompido funciona como fulcro para rotação do primeiro molar, durante a 


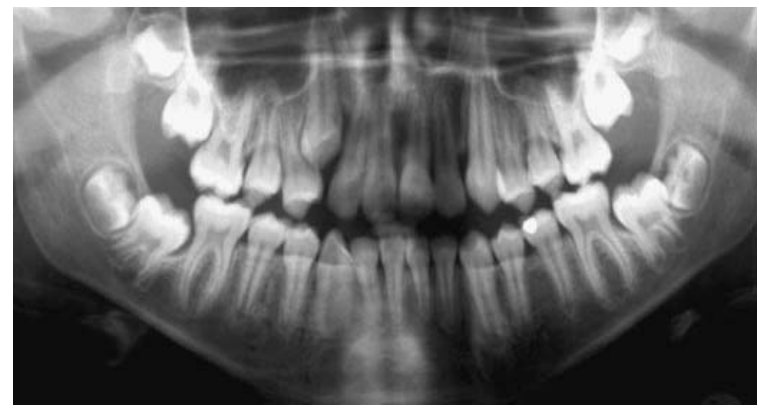

FIGURA 10A - Radiografia inicial (Caso 1).

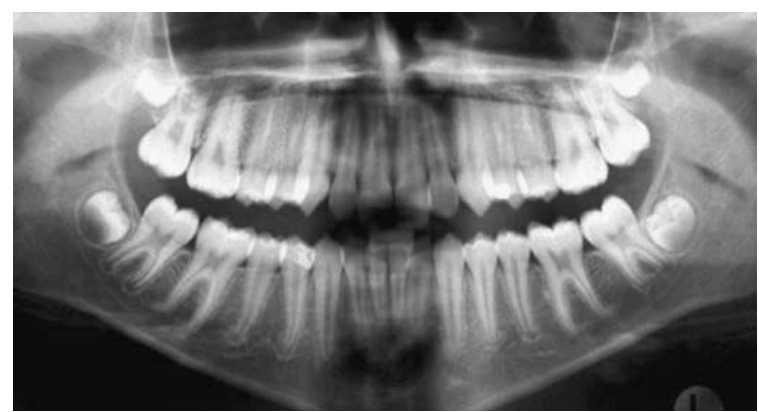

FIGURA 10C - Radiografia inicial (Caso 2).

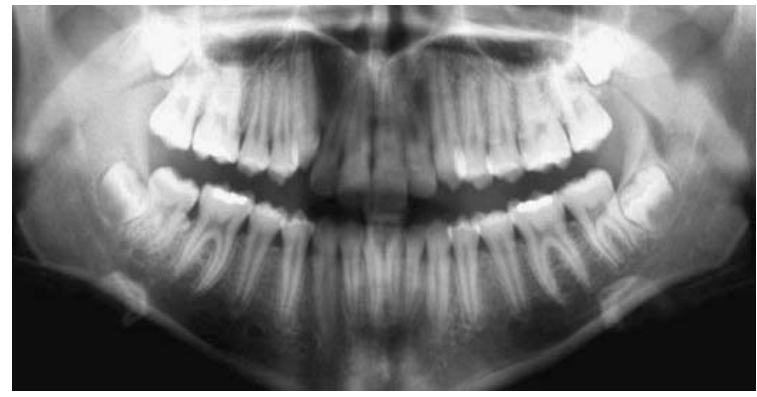

FIGURA 10E - Radiografia inicial (Caso 3).

distalização com o aparelho Pêndulo. A mecânica da distalização do primeiro molar em relação ao segundo molar está ilustrada na figura 11, extraída do referido artigo ${ }^{24}$. O ponto de contato intra-ósseo do primeiro molar com o segundo molar não irrompido determina maior inclinação do primeiro molar para distal (Fig. 11A). O ponto de contato das coroas do primeiro e segundo molares reduz a inclinação axial do primeiro molar durante a distalização (Fig. 11B). Contudo, a casuística reduzida na presente pesquisa não permite discutir essa importante premissa científica.

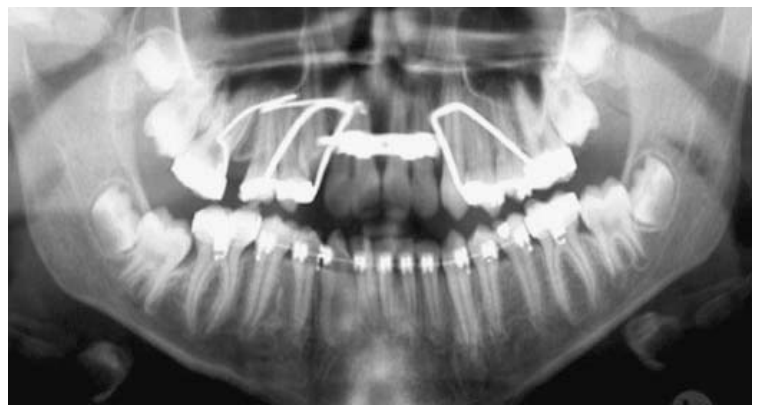

FIGURA 10B - Radiografia pós-distalização (Caso 1).

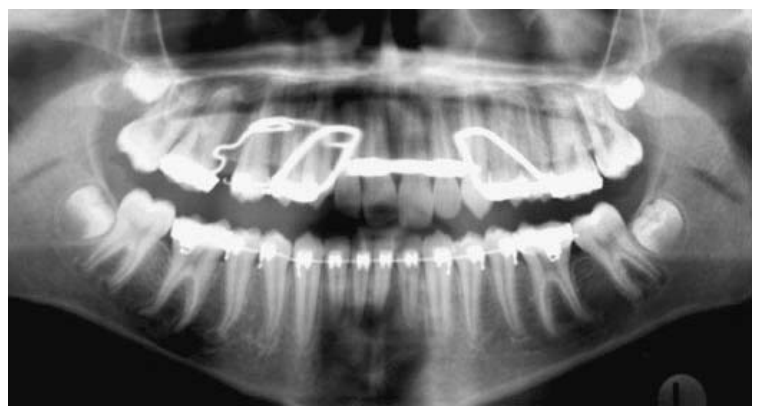

FIGURA 10D - Radiografia pós-distalização (Caso 2).

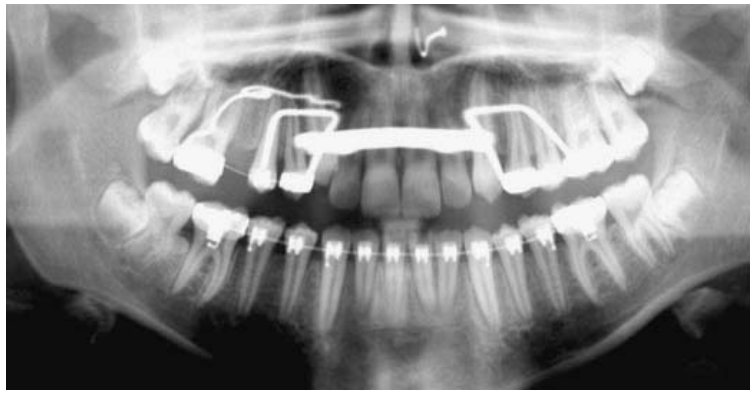

FIGURA 10F - Radiografia pós-distalização (Caso 3).

Quando comparado com o comportamento dos molares, em pesquisa prévia com distalização bilateral em radiografia panorâmica ${ }^{32}$, a inclinação dos molares se deu no mesmo sentido, ou seja, a coroa inclinou para distal. O primeiro molar do lado direito inclinou $11,5^{\circ}$ no distalizador unilateral e $19^{\circ}$ no distalizador bilateral, enquanto o segundo molar inclinou $21^{\circ}$ no Pendex unilateral e $16^{\circ}$ no Pendex bilateral. $\mathrm{O}$ fato é que os molares superiores inclinaram para distal, independentemente do Pendex ser aplicado bilateral ou unilateralmente.

$\mathrm{O}$ que não se sabia, então, era o que aconte- 


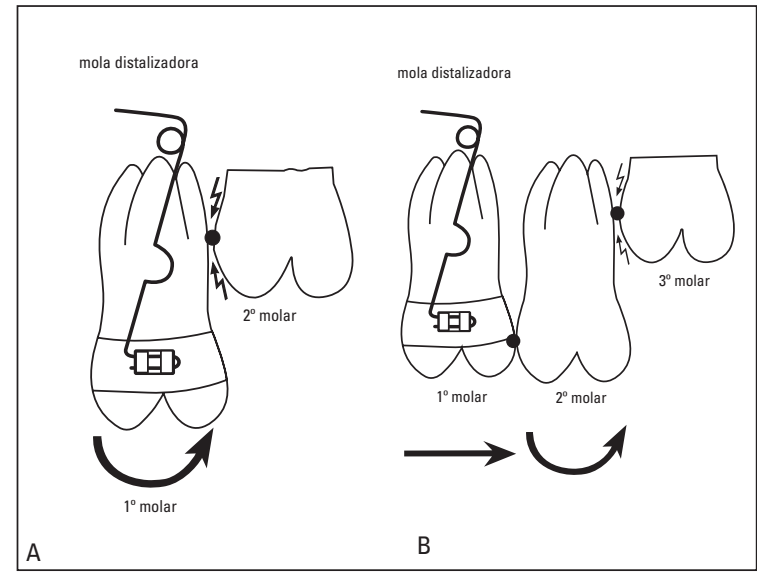

FIGURA 11 - Influência mecânica dos segundos molares superiores na resposta dos primeiros molares superiores frente ao distalizador intrabucal Pêndulo (extraído de Kinzinger, G.S.M. et al. ${ }^{24}, 2004$ ). Em A) o efeito de fulcro gerado pelo ponto de contato intra-ósseo entre o primeiro e o segundo molar, B) a menor inclinação axial para distal do primeiro molar quando o ponto de contato entre o primeiro e segundo molar está na boca.

cia com os molares que não receberam a mola de TMA, que teoricamente funcionariam como ancoragem. Esses molares mantiveram suas inclinações mesiodistais iniciais, como se verifica nas radiografias pós-distalização (Fig. 10) e se comprova nas tabelas 1 e 2. Os molares do lado esquerdo parecem ter funcionado bem como ancoragem. Pelo menos não mudaram de posição, enquanto os molares do lado direito eram distalizados.

A preservação da posição mesiodistal dos mo- lares do lado de ancoragem pressupõe que os molares ditos de ancoragem, o lado que não recebeu a mola distalizadora, mantêm-se estabilizados durante a distalização dos molares do lado ativo.

Os distalizadores unilaterais, pelo menos em princípio, substituiriam o AEB com força excêntrica. No AEB a assimetria da força é determinada pela assimetria do braço externo. $\mathrm{O}$ braço externo maior e mais aberto provocaria uma liberação de força maior. $\mathrm{O}$ inconveniente do AEB excêntrico refere-se à variável cooperação.

\section{CONCLUSÃO}

Os resultados indicam que é possível induzir inclinação da coroa dos molares superiores para distal quando se aplica um distalizador intrabucal unilateral, (no caso específico da presente pesquisa, o aparelho Pendex). O dado mais importante refere-se à preservação da inclinação mesiodistal dos molares contra-laterais. Como foi observado efetividade nesses três casos tratados com o aparelho Pendex de ação unilateral, cabe a realização de uma pesquisa com amostra maior e de caráter prospectivo.

Distalization of the upper molars with the Pend-X appliance: a pilot study with panoramic radiographs

\begin{abstract}
Aim: the current study focuses on the immediate unilateral distalization of the upper molars with the unilateral Pend-X appliance. Methods: in three adolescent patients in the permanent dentition with Class II subdivision 1 malocclusion, the TMA loop was placed in the right side. Therefore, the first and second upper right molars were distalized with the Pend-X appliance. Panoramic radiographs taken before and after distalization were used to measure the mesiodistal axial inclination of the upper molars and the results were compared to those obtained with the bilateral Pend-X. Results and Conclusion the findings show that the left molars kept their original mesiodistal inclination, suggesting that the anchorage was maintained, whilst the right molars were partially inclined in a distal direction, similarly to what occurs when conventional Pend-X is used to distalize molars bilaterally. The first molars showed an $11.5^{\circ}$ distal inclination while the second molars presented a $21^{\circ}$ distal inclination.
\end{abstract}

Key words: Pend-X appliance. Class II malocclusion. Distalization. Unilateral distalization. Dentofacial deformities. 


\section{REFERÊNCIAS}

1. AIDAR, L. A. A. et al. Jones Jig e barra transpalatina - tratamento alternativo na correção unilateral da má oclusão Classe II divisão 2, subdivisão. R Dental Press Ortodon Ortop Facial, Maringá, v. 5, n. 3, p. 58-63, maio/jun. 2000

2. ASHMORE, J. L. et al. A 3-dimensional analysis of molar movement during headgear treatment. Am J Orthod Dentofacial Orthop, St. Louis, v. 121, no. 1, p. 18-30, Jan. 2002.

3. BALDINI, G. Unilateral headgear: lateral forces as unavoidable side effects. Am J Orthod, St. Louis, v. 77, p. 333-340, 1980.

4. BAUMRIND, S. et al. Quantitative analysis of the orthodontic and orthopedic effects of maxillary traction. Am J Orthod, St. Louis, v. 84, no. 5, p. 384-398, Nov. 1983.

5. BORTOLOZO, M. A. et al. Distalização de molares superiores com o pendulum/pendex: o aparelho, seu modo de ação, possibilidades e limitações. R Dental Press Ortodon Ortop Facial, Maringá, v. 6, n. 4, p. 43-50, jul./ago. 2001

6. BURKHARDT, D. R.; McNAMARA JR., J. A.; BACCETTI, T. Maxillary molar distalization or mandibular enhancement: a cephalometric comparison of comprehensive orthodontic treatment including the pendulum and the Herbst appliances. Am J Orthod Dentofacial Orthop, St. Louis, v. 123, no. 2, p. 108-116, Feb. 2003

7. BUSSICK, T. J.; McNAMARA JR., J. A. Dentoalveolar and skeletal changes associated with the pendulum appliance. Am J Orthod Dentofacial Orthop, St. Louis, v. 117, no. 3, p. 333-343, Mar. 2000.

8. BYLOFF, F. K et al. An implant to eliminate anchorage loss during molar distalization: a case report involving the Graz implantsupported pendulum. Int J Adult Orthodon Orthognath Surg, Lombard, v. 15, no. 2, p. 129-137, 2000.

9. BYLOFF, F. K . et al. Distal molar movement using the pendulum appliance. Part 2: the effects of maxillary molar root uprighting bends. Angle Orthod, Appleton, v. 67, no. 4, p. 261-270, 1997.

10. BYLOFF, F. K.; DARENDELILER, M. A. Distal molar movement using the pendulum appliance. Part 1: clinical and radiological evaluation. Angle Orthod, Appleton, v. 67, no. 4, p. 249-260, 1997.

11. CHAQUÉS-ASENSI, J.; KALRA, V. Effects of the pendulum appliance on the dentofacial complex. J Clin Orthod, Boulder, v. 35, no. 4, p. 254-257, 2001

12. FREITAS, B. V. et al. Distalização unilateral de primeiros molares superiores com o aparelho Jones Jig: apresentação de 2 casos clínicos. Ortodontia, São Paulo, v. 28, n. 3, p. 31-40, set./dez. 1995.

13. FUZIY, A. Estudo das alterações sagitais, verticais e transversais decorrentes da distalização dos molares superiores com o aparelho Pendulum. 2001. 283 f. Tese (Doutorado)-Faculdade de Odontologia de Bauru, Universidade de São Paulo, Bauru, 2001.

14. GHAFARI, J. Modified Nance and lingual appliances for unilateral tooth movement. J Clin Orthod, Boulder, v. 19, no. 1 p. 30-33, Jan. 1985.

15. GHOSH, J.; NANDA, R. S. Evaluation of an intraoral maxillary molar distalization technique. Am J Orthod Dentofacial Orthop, St. Louis, v. 110, no. 6, p. 639-646, Dec. 1996.

16. HAYDAR, S.; UNER, O. Comparison of Jones jig molar distalization appliance with extraoral traction. Am J Orthod Dentofacial Orthop, St. Louis, v. 117, no. 1, p. 49-53, Jan. 2000.

17. HILGERS, J. J. A palatal expansion appliance for non-compliance therapy. J Clin Orthod, Boulder, v. 25, no. 8, p. 491-497, Aug. 1991.

18. HILGERS, J. J. Hyperefficient orthodontic treatment using tandem machanics. Semin Orthod, Philadelphia, v. 4, no. 1, p. 17 25, Mar. 1998.

19. HILGERS, J. J. The pendulum appliance for Class II non-compliance therapy. J Clin Orthod, Boulder, v. 26, no. 11, p. 706-714, Nov. 1992.

20. JANSON, G. R. P.; METAXAS, A. ; WOODSIDE, D. G.; FREITAS, M. R.; PINZAN, A. Three-dimensional evaluation of skeletal and dental asymmetries in Class II, subdivision malocclusions. Am J Orthod Dentofacial Orthop, St. Louis, v. 119, no. 4, p. 406-418, 2001

21. JOSEPH, A. A.; AUTCHART, C. J. An evaluation on the pendulum "distalizing" appliance. Semin Orthod, Philadelphia, v. 6, no. 2, p. 129-135, 2000

22. KINZINGER, G. et al. Modified pendulum appliance including distal screw and uprighting activation for non-compliance therapy of Class II malocclusion in children and adolescents. J Orofac Orthop, Munich, v. 61, no. 3, p. 175-190, 2000

23. KINZINGER, G.; FRITZ, U. B.; DIETRICH, P. R. Bipendulum and quad pendulum for non-compliace molar distalization in adult patients. J Orofac Orthop, Munich, v. 63, no. 2, p. 154-162, Mar. 2002.

24. KINZINGER, G. et al. Efficiency of a pendulum appliance for molar distalization related to second and third molar eruption stage. Am J Orthod Dentofacial Orthop, St. Louis, v. 125, no. 1, p. 8-23, Jan. 2004

25. LEWIS, D. H.; FOX, N. A. Distalização sem ancoragem extrabucal: utilização de um aparelho removível superior para distalização de primeiros molares superiores. R Dental Press Ortodon Ortop Facial, Maringá, v. 2, n. 3, p. 50-51, maio/jun. 1997.

26. LUCATO, A. S. et al. Sliding Jig: confecção e mecanismo de ação. Rev Clín Ortodon Dental Press, Maringá, v. 2, n. 6, p. 10-17, dez. 2003/jan. 2004

27. MELSEN, B. Effects of cervical anchorage during and after treatment: an implant study. Am J Orthod, St. Louis, v. 73, no. 5, p. 526-540, May 1978

28. OLIVEIRA, J. M. M.; ETO, L. F. Avaliação radiográfica dos efeitos do Jones Jig em distalizações intra-bucais: um estudo piloto. R Dental Press Ortodon Ortop Facial, Maringá, v. 9, n. 5, p. 20-27, set./out. 2004.

29. PIERINGER, M.; DROSCHI, H.; PERMANN, R. Distalização com um aparelho de Nance e molas. R Dental Press Ortodon Ortop Facial, Maringá, v. 3, n. 2, p. 48-49, mar./abr. 1998.

30. POULTON, D. R. The influence of extraoral traction. Am J Orthod, St. Louis, v. 53, no. 1, p. 8-18, Jan. 1967.

31. SANTOS, E. C. A. et al. Distalização dos molares superiores com aparelho Pendex: estudo cefalométrico prospectivo. R Dental Press Ortodon Ortop Facial, Maringá (prelo).

32. SANTOS, E. C. A. et al. Distalização dos molares superiores com aparelho Pendex: avaliação mediante radiografia panorâmica. J Bras Ortodon Ortop Facial, Curitiba. (prelo).

33. SANTOS, E. C. A. et al. Distalização dos molares superiores com aparelho Pendex: estudo em modelos de gesso. R Dental Press Ortodon Ortop Facial, Maringá. (prelo).

34. SCUZZO, G.; PISANI. F.; TAKEMOTO, K. Maxilary molar distalization with a modified pendulum appliance. J Cin Orthod, Boulder, v. 33, no. 11, p. 645-650, Nov. 1999.

35. SCUZZO, G. et al. The modified pendulum appliance with removable arms. J Cin Orthod, Boulder, v. 34, no. 4, p. 244-246, 2000.

36. SILVA FILHO, O. G. et al. Distalizador "Jones Jig": um método alternativo para a distalização de molares superiores. R Dental Press Ortodon Ortop Facial, Maringá, v. 5, n. 4, p. 18-26, jul./ ago. 2000.

37. SILVEIRA, G. S.; ETO, L. F. Aparelho distalizador intra-bucal Distal Jet: confecção laboratorial e manejo clínico. Rev Clín Ortodon Dental Press, Maringá, v. 3, n. 4, p. 14-22, ago./set. 2004.

38. SILVEIRA, G. S.; ETO, L. F. Avaliação radiográfica dos efeitos do aparelho Distal Jet nas distalizações intrabucais: um estudo piloto. R Dental Press Ortodon Ortop Facial, Maringá, v. 9, n. 2, p. 69-78, mar./abr. 2004

39. SUGUINO, R.; FURQUIM, L. Z.; RAMOS, A. L. O aparelho Jones Jig. R Dental Press Ortodon Ortop Facial, Maringá, v. 5, n. 3, p. 83-116, maio/jun. 2000.

40. TANER, T. U. et al. A comparative analysis of maxillary tooth movement produced by cervical headgear and pende-x appliance. Angle Orthod, Appleton, v. 73, no. 6, p. 686-691, Dec. 2003.

41. URSI, W.:ALMEIDA, G. A. Cooperação mínima utilizando o pêndulo de Hilgers. R Dental Press Ortodon Ortop Facial, Maringá, v. 7, n. 2, p. 87-123, mar./abr. 2002.

\section{Endereço para correspondência}

Omar Gabriel da Silva Filho

Setor de Ortodontia do Hospital de Reabilitação de Anomalias

Craniofaciais da USP - Rua Sílvio Marchione, 3-20 / Vila Universitária

CEP: 17.043-900 - Bauru/SP

E-mail: ortoface@travelnet.com.br 